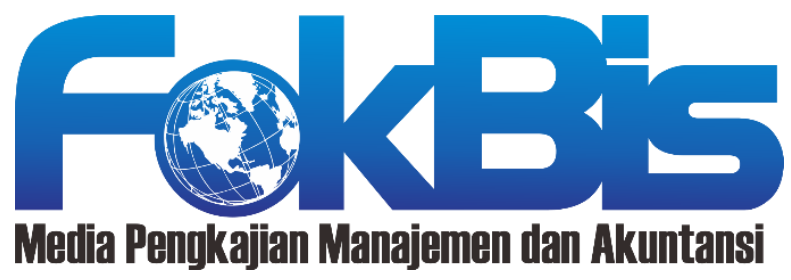

http://journal.stieputrabangsa.ac.id/index.php/fokbis/index

ISSN: 2623-2480/ P-ISSN: 1693-5209

\section{PENGARUH SELF EFFICACY, LOCUS OF CONTROL DAN KOMITMEN ORGANISASI TERHADAP KINERJA PENDAMPING SOSIAL}

\section{(Studi pada Pendamping Sosial PKH Kabupaten Kebumen)}

\section{Dani Rizana}

STIE Putra Bangsa, Kebumen, Indonesia

email: danirizana@gmail.com

\section{Article Information}

\section{History of Article:}

Received October $7^{\text {th }}, 2019$

Accepted October $9^{\text {th }}, 2019$

Published December 23 ${ }^{\text {rd }}, 2019$

DOI:

10.32639/fokusbisnis.v\%vi\%i.351

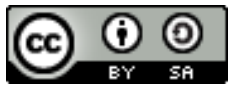

\begin{abstract}
The purpose of this study was to study the organizational commitment, organizational culture and environment towards the Family Hope (PKH) companion program at the Social Service Office of the PPKB Kebumen Regency. This research is a survey research with the influence of Self efficacy (X1), locus of control (X2), and organizational commitment (X3) on the performance of companion in the Social Service Office of Kebumen Regency PPKB. The population is all companions taking 240 people, while the sample is taken 150 companions. After analyzing the data, the following results and conclusions are obtained: (1) selfefficacy influences the performance of the companion. (2) The locus of control shows a positive and significant effect on the performance of the companion. (3) Organizational commitment shows a positive and significant impact on the performance of the companion. (4) Self efficacy, locus of control and organizational commitment have a significant (simultaneous) effect on the performance of PKH Social Assistance in Kebumen District and provide a $56.10 \%$ increase in the performance of PKH companions $\left(R^{2}\right.$ $=0.561$ )
\end{abstract}

Keywords: Self-Efficacy, Locus of Control, Commitment

\title{
PENDAHULUAN
}

Pendamping Sosial PKH merupakan Sumber Daya Manusia (SDM) yang direkrut oleh Kementerian Sosial sebagai garda terdepan terdepan untuk menanggulangi kemiskinan. Sebagai pekerja sosial, peran pendamping sangat dibutuhkan dalam mendukung pemerintah untuk menggulangi permasalahan kemiskinan. Sebagai Pendamping Sosial PKH tentunya harus siap menerima apa konsekuensi yang akan terjadi di lapangan dalam bertugas. keluarga penerima manfaat membutuhkan peran serta secara langsung oleh Pendamping Sosial PKH untuk memperlancar kegiatan administrasi maupun teknis. Peran penting Pendamping Sosial PKH di Kabupaten Kebumen menjadi tolak ukur keberhasilan dalam mengurangi angka kemiskinan, sehingga Pendamping Sosial PKH dituntut harus bekerja secara produktif, 
efektif, dan efisien sebagai peksos yang profesional. Bekerja sebagai Pendamping Sosial PKH bukanlah pekerjaan yang mudah dijalankan karena bekerja secara langsung berhadapan dengan masyarakat di lapangan, dimana tentunya akan banyak bertemu dengan berbagai macam orang yang mempunyai karakteristik yang berbedah-beda, sehingga sebagai Pendamping Sosial PKH harus dituntut mampu beradaptasi dengan berbagai macam karakter orang yang di jumpai dilapangan, khususnya penerima bantuan sosial atau yang disebut sebagai Keluarga Penerima Manfaat (KPM).

Kabupaten kebumen adalah salah satu kabupaten yang berada di Jawa Tengah yang termasuk kabupaten termiskin kedua di Jawa Tengah. Hal tersebut jelas menggambarkan bahwa Kabupaten Kebumen tingkat kemiskinan masyarakatnya masih tinggi dibandingkan dengan kabupaten lain

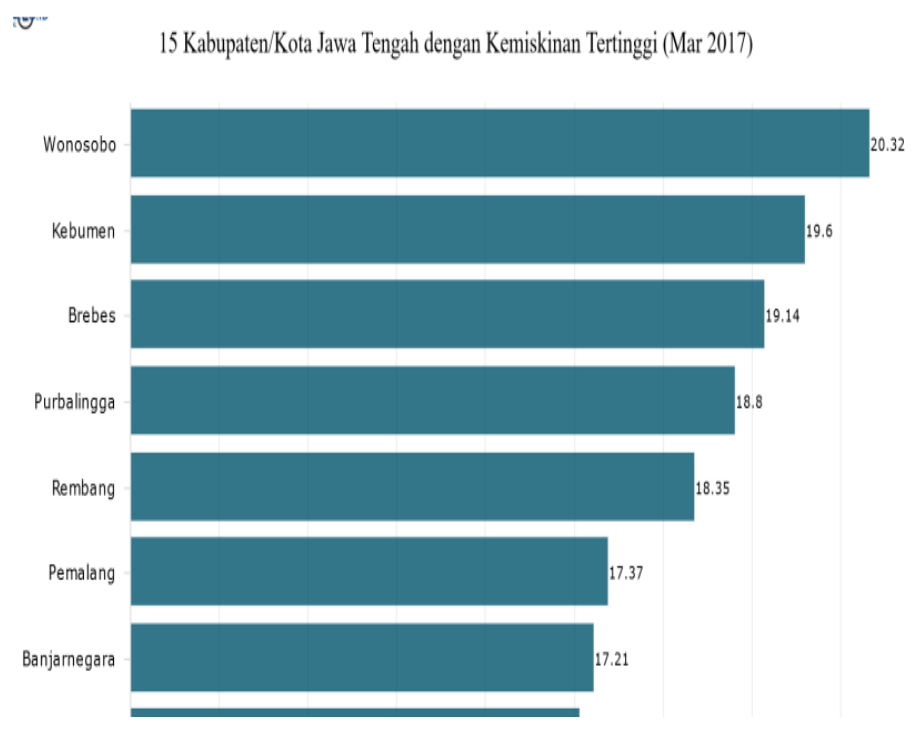

Gambar 1. Grafik Kemiskinan Jawa Tengah

Dari gambar 1 diatas dapat dilihat bahwa kemiskinan di Kabupaten Kebumen masih mendududuki peringkat ke 2 Provinsi Jawa Tengah Per maret 2017.

Pendamping sosial PKH di Kabupaten Kebumen per januari 2019 sejumlah 240, namun awal januari 2019 banyak pendamping Sosial yang mengundurkan diri dikarenakan diterima menjadi pegawai dipekerjaan lain, sehingga ada beberapa pendamping yang ditugasi merangkap pekerjaannya untuk mengisi sementara kekosongan tersebut sampai ada lagi perekrutan pendamping sosial yang baru. Pendamping yang ditugasi merangkap pekerjaannya secara tidak langsung akan mengalami penurunan Self Efficacy sehingga akan berpengaruh terhadap kinerjanya, karena akan mendapatkan tugas tambahan sehingga menambah beban pendampingan pendamping yang lain di sisi lain keyakinan diri untuk dapat menyelesaiakn pekerjaannya jadi berkurang. Morrison dalam Fadzilah (2006) memberikan pengertian Self Efficacy sebagai kecenderungan seseorang melibatkan diri dalam kegiatan yang mengarah sasaran.

Selain Self Efficacy, locus of control pendamping social PKH Kabupaten Kebumen terhadap komitmen kinerjanya juga masih kurang maksimal. Hal ini diamati dari hasil pengisian laporan bulanan memlaui eppkh masih ada beberapa kecamatan yang mengabaikan pelaporan bulanan pada eppkh, dari hal tersebut, maka locus of control pendamping masih rendah sehingga kinerjanya kurang maksimal. (Helmy, Adawiyah, \& Banani, 2019)

Komitmen pendamping PKH Kabupaten Kebumen masih sangat perlu ditingkatkan agar dapat melaksanakan pekerjaan dengan maksimal, masih banyak pendamping yang belum mampu memaksimalkan kinerjanya, hal ini ditandai oleh masih banyknya pendamping yag mempunyai pekerjaan diluar PKH (double job) sehingga sehingga pendamping PKH di Kabupaten Kebumen masih belum menunjukkan kinerja yang maksimal, dan secara langsung turut mempengaruhi komitmen organisasi yang 
telah diterapkan. Menurut Meyer dan Allen dalam Umam (2010:258) Komitmen organisasi sebagai suatu konstruk psikologi yang merupakan karakteristik hubungan anggota organisasi dengan organisasinya. Pernyataan ini mewakili dari faktor psikologi yang dapat mempengaruhi kinerja seseorang.

\section{Kinerja Pegawai}

Mas'ud (2004) mengemukakan bahwa kinerja adalah hasil pencapaian dari usaha yang telah dilakukan yang dapat diukur dengan indikator-indikator tertentu. Indikator kinerja individual antara lain bersemangat kerja yang tinggi, melakukan tugas dengan baik (seperti, menyimpan data dengan tepat, datang tepat waktu), dapat bekerja sama dengan karyawan lain, memberikan inisiatif dan kemandirian dalam bekerja, menggunakan pengetahuan dan ketrampilan dengan baik dalam bekerja, memahami peraturan dengan baik dan mengunakan peraturan dalam bekerja, perhatian terhadap pekerjaan yang ditugaskan dan mau melakukan usaha yang lebih keras dalam menyelesaikan pekerjaan dengan baik

\section{Self Efficacy}

Menurut Bandura (1997) mendefinisikan self efficacy sebagai judgment individu atas kemampuan mereka untuk mengorganisasi dan melakukan serangkaian tindakan yang diperlukan untuk mencapai tingkat kinerja yang ditentukan. Self efficacy menurut Bandura (1997) dapat ditumbuhkan dan dipelajari melalui empat sumber yaitu kinerja atau pengalaman masa lalu, model perilaku (mengamati orang lain yang melakukan tindakan yang sama), persuasi dari orang lain serta keadaan faktor fisik dan emosional. Pencapaian prestasi merupakan pengharapan efficacy yang terbesar karena didasarkan pada pengalaman-pengalaman pribadi individu berupa keberhasilan atau kegagalan. Self efficacy adalah sebagai judgment individu atas kemampuan mereka untuk mengorganisasi dan melakukan serangkaian tindakan yang diperlukan untuk mencapai tingkat kinerja yang ditentukan.

\section{Locus of Control}

Locus of control menurut Kreitner dan Kinicki (2003) terdiri dari dua konstruk yaitu internal dan eksternal, dimana apabila seseorang yang meyakini bahwa apa yang terjadi selalu berada dalam kontrolnya dan selalu mengambil peran serta bertanggung jawab dalam setiap pengambilan keputusan termasuk dalam internal locus of control, sedangkan seseorang yang meyakini bahwa kejadian dalam hidupnya berada diluar kontrolnya termasuk dalam external locus of control. Spector dalam Falikhatun (2003) menyatakan bahwa berdasarkan teori locus of control, seseorang yang merasa tidak nyaman dalam satu lingkungan budaya tertentu akan mengalami ketidakberdayaan dan kekhawatiran. Locus of control merupakan keyakinan masing-masing individu karyawan tentang kemampuannya untuk bisa mempengaruhi semua kejadian yang berkaitan dengan dirinya dan pekerjaannya.

\section{Komitmen Organisasi}

Komitmen Organisasional menurut (Newstrom dan Davis, 1997:259-60) dalam Indra menjelaskan bahwa: "pegawai yang memiliki komitmen terhadap organisasi biasanya memiliki catatan kehadiran yang baik menunjukan kesetiaan secara sukarela terhadap kebijakan perusahaan dan memiliki tingkat pergantian yang rendah secara khusus, pengetahuan mereka yang luas tentang pekerjaan sering terwujud menjadi pelanggan yang setia yang membeli lebih banyak yang merekomendasikan kepada pelanggan lain serta dia membayar harga yang lebih". Komitmen Organisasional menurut (Luthans 2006:249) menjelaskan bahwa: "sikap yang merefleksikan loyalitas karyawan pada organisasi dan proses berkelanjutan dimana anggota organisasi mengekspresikan perhatiannya terhadap organisasi dan keberhasilan serta kemajuan yang berkelanjutan".

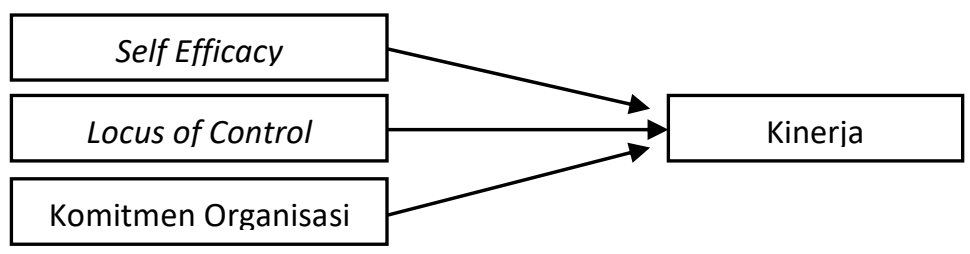




\section{Gambar 2. Kerangka Penelitian}

Hipotesis dalam penelitian ini adalah :

H1 : self efficacy berpengaruh positif terhadap kinerja pendamping sosial.

H2 : Locus of control berpengaruh positif terhadap kinerja pendamping sosial

H3 : Komitmen organisasi berpengaruh positif terhadap kinerja pendamping sosial.

\section{METODE}

\section{Populasi dan Sampel}

Populasi didalam penelitian ini adalah seluruh pendamping PKH Kabupaten Kebumen yang berjumlah 240 orang. Untuk mengetahui berapa besar sampel yang mewakili populasi maka digunakan rumus slovin (Umar, 2002). Jadi ukuran sampel yang diambil dalam penelitian ini sebanyak 150 responden.

\section{Karakteristik Responden}

Sampel dalam penelitan ini adalah pendamping PKH diKabupaten Kebumen sebanyak 150 orang. Untuk mengetahui profil responden tersebut, maka karakteristik yang digunakan dilihat berdasarkan jenis kelamin, umur, tingkat pendidikan dan lama kerja.

Tabel 1.

Karakteristik Responden Berdasarkan Jenis Kelamin

\begin{tabular}{cccc}
\hline \multirow{2}{*}{ No. } & \multirow{2}{*}{ Jenis Kelamin } & \multicolumn{2}{c}{ Jumlah Responden } \\
\cline { 3 - 4 } & & Dalam Angka & Prosentase (\%) \\
\hline 1. & Laki-laki & 33 & 22 \\
2. & Perempuan & 117 & 78 \\
\hline & Jumlah & 150 & 100 \\
\hline
\end{tabular}

sumber: Data diolah, 2019

Berdasarkan Tabel di atas dapat diketahui mayoritas responden berjenis kelamin perempuan. Responden pendamping sosial PKH berdasarkan tingkat usia dapat dilihat pada Tabel 2 berikut ini.

Tabel 2.

Karakteristik Responden Berdasarkan Tingkat Usia

\begin{tabular}{cccc}
\hline \multirow{2}{*}{ No. } & \multirow{2}{*}{ Tingkat Usia } & \multicolumn{2}{c}{ Jumlah Responden } \\
\cline { 3 - 4 } & & Dalam Angka & Prosentase (\%) \\
\hline 1. & $20-30$ tahun & 104 & 63,33 \\
2. & $30-40$ tahun & 41 & 27,33 \\
3. & $>40$ tahun & 5 & 3,33 \\
\hline & Jumlah & 150 & 100 \\
\hline
\end{tabular}

sumber: Data diolah, 2019

berdasarkan table 2, sebagian besar responden berumur antara 20-30 tahun. Rincian penggolongan responden berdasarkan tingkat pendidikannya, dapat dilihat pada Tabel 3 berikut ini. 
Tabel 3.

Karakteristik Responden Berdasarkan Tingkat Pendidikan

\begin{tabular}{cccc}
\hline \multirow{2}{*}{ No. } & \multirow{2}{*}{ Strata } & \multicolumn{2}{c}{ Jumlah Responden } \\
\cline { 3 - 4 } & & Dalam Angka & Prosentase (\%) \\
\hline 1. & D3 & 35 & 23,33 \\
2. & S1 & 113 & 75,33 \\
3. & S2 & 2 & 1,33 \\
\hline & Jumlah & 150 & 100 \\
\hline
\end{tabular}

sumber: Data diolah, 2019

Terlihat pada Tabel 3 bahwa sebagian besar responden dengan tingkat pendidikan sarjana S1. Lama kerja responden dalam penelitian ini terbagi ke dalam empat golongan. Untuk lebih jelasnya dapat dilihat pada Tabel 4 berikut ini.

Tabel 4.

Karakteristik Responden Berdasarkan Lama Kerja

\begin{tabular}{|c|c|c|c|}
\hline \multirow{2}{*}{ No. } & \multirow{2}{*}{ Lama Kerja } & \multicolumn{2}{|c|}{ Jumlah Responden } \\
\hline & & Dalam Angka & Prosentase (\%) \\
\hline 1. & 5 tahun & 86 & 57,33 \\
\hline 2. & 3 tahun & 54 & 36 \\
\hline \multirow[t]{2}{*}{3.} & 1 tahun & 10 & 6,67 \\
\hline & Jumlah & 150 & 100 \\
\hline
\end{tabular}

Berdasarkan Tabel 4 di atas, dapat diketahui bahwa sebagian besar responden telah bekerja selama 5 tahun

\section{HASIL DAN PEMBAHASAN}

\section{Analisis Data}

Kuesioner instrumen yang telah diuji validitas dan reliabilitasnya menggunakan bantuan SPSS dinyatakan valid dan reliable selanjutnya data kuesinoner dilakukan analisis statistika untukmenguji butir hasil tabulasi kuesioner yang telah diisi responden. Analisis ini dilakukan dengan melakukan pengujian berikut:

\section{Multikolinieritas}

Tidak adanya multikolinearitas ditentukan dengan angka VIF dibawah 10 dan tolerance diatas 0,1 (Ghozali, 2009:95). Hasil analisis data dengan Program SPSS diperoleh output sebagai berikut:

Tabel 5. Uji Multikolinieritas

\begin{tabular}{cr}
\hline \multicolumn{2}{c}{ Collinearity Statistics } \\
\hline Tolerance & \multicolumn{1}{c}{ VIF } \\
\hline 0,471 & 2,125 \\
0,665 & 1,503 \\
0,657 & 1,523 \\
\hline \multicolumn{2}{l}{ Sumber: Data diolah, 2019}
\end{tabular}


Dari tabel tersebut dapat diketahui bahwa nilai tolerance diatas 0,1 dan VIF dibawah angka 10 sehingga model regresi tidak terjadi multikolinieritas.

\section{Heteroskedastisitas}

Model regresi yang baik adalah apabila tidak terjadi heteroskedastisitas dengan pengujian sebagai berikut:

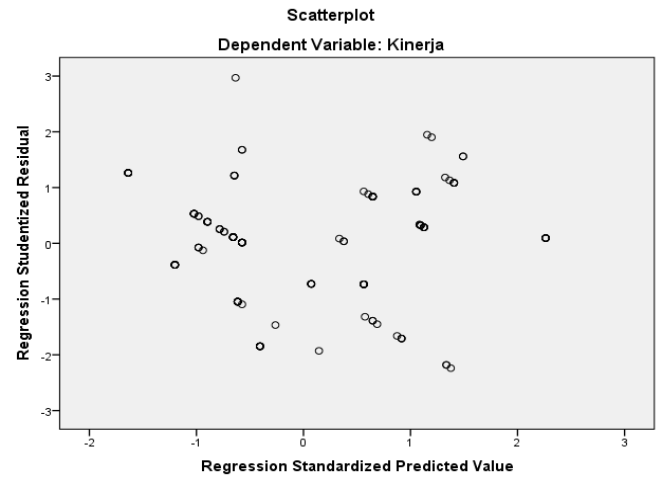

Gambar 3. Uji Heteroskedastisitas Persamaan

Berdasarkan gambar 3 menunjukkan bahwa tidak ada pola tertentu seperti titik-titik yang membentuk suatu pola tertentu yang teratur (melebar, menyempit), tidak ada pola yang jelas sehingga dapat disimpulkan model regresi pada penelitian ini tidak terjadi heteroskedastisitas.

\section{Normalitas}

Model regresi yang baik adalah distribusi data normal atau mendekati normal. Berdasarkan gambar 4 (Normal P-P Plot of Regression Standardized Residual) diketahui bahwa data menyebar di sekitar garis diagonal dan mengikuti arah garis diagonal, maka model regresi tersebut memenuhi asumsi normalitas.

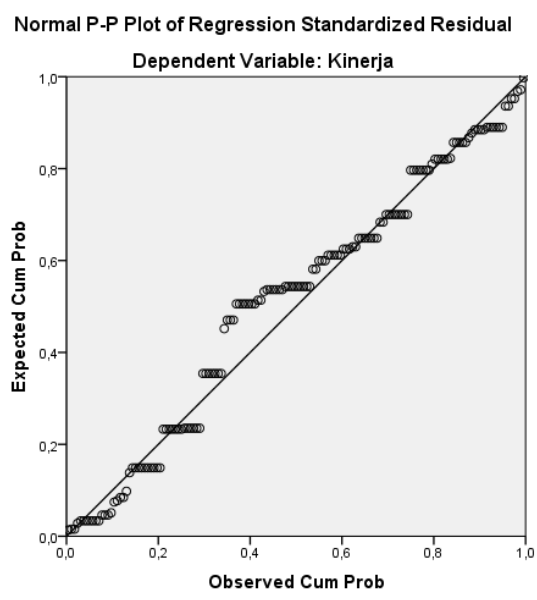

Gambar 4. Uji Normalitas Persamaan

\section{Analisis Regresi Linier Ganda}

Analisa regresi linier berganda dilakukan untuk mengetahui pengaruh langsung variabel self efficacy, locus of control dan komitmen organisasi terhadap kinerja Pendamping PKH Kabupaten Kebumen. Berikut adalah hasil dari output spss 22.0. 
Tabel 6. Hasil Analisis Regresi

\begin{tabular}{|c|c|c|c|c|c|}
\hline \multirow[t]{2}{*}{ Model } & \multicolumn{2}{|c|}{$\begin{array}{c}\text { Unstandardized } \\
\text { Coefficients }\end{array}$} & \multirow{2}{*}{$\begin{array}{c}\begin{array}{c}\text { Standardized } \\
\text { Coefficients }\end{array} \\
\frac{\text { Beta }}{r}\end{array}$} & \multirow[t]{2}{*}{$\mathrm{t}$} & \multirow[t]{2}{*}{ Sig. } \\
\hline & B & Std. Error & & & \\
\hline (Constant) & 4,217 & 1,357 & & 3,108 & ,002 \\
\hline Self of Efficacy & ,086 & ,131 & ,052 & ,657 &, 512 \\
\hline Locus of Control & 927 & 107 & ,575 & 8,641 & ,000 \\
\hline Komitmen Organisasi & ,495 & 105 & ,316 & 4,724 & ,000 \\
\hline
\end{tabular}

Sumber: Data diolah, 2019

Berdasarkan hasil output SPSS 22 didapat koefisien regresi sehingga persamaan regresinya dapat disusun sebagai berikut.

$Y=4,217+0,086 X_{1}+0,927 X_{2}+0,495 X_{3}+e$

\section{Pengujian Hipotesis}

Untuk menguji koefisien regresi secara keseluruhan maupun sendiri-sendiri pengaruh self-efficacy, locus of control dan komitmen organisasi terhadap kinerja digunakan uji t dan uji F.

Uji t untuk mengetahui pengaruh secara parsial variabel self-efficacy, locus of control dan komitmen organisasi terhadap kinerja. Pedoman penarikan kesimpulan yaitu Tidak ada pengaruh signifikan apabila $\mathrm{t}_{\text {hitung }}<\mathrm{t}$ tabel dan signifikansi $>0,05$ dan terdapat pengaruh signifikan apabila $t_{\text {hitung }}>\mathrm{t}$ tabel dan signifikansi $<0,05$. Berdasarkan hasil analisis regresi pada Tabel 7 diatas dapat dilihat bahwa:

a) Variabel self-efficacy mempunyai nilai thitung sebesar 0,657 $<t_{\text {tabel }} 1,976$ dengan tingkat signifikansi $0,512>0,05$ ini berarti variabel self-efficacy tidak berpengaruh signifikan terhadap kinerja.

b) Variabel locus of control mempunyai nilai hasil thitung sebesar 8,641 $>t_{\text {tabel }}$ 1,976 dengan tingkat signifikansi $0,000<0,05$ ini berarti variabel locus of control berpengaruh signifikan terhadap kinerja.

c) Variabel komitmen organisasi mempunyai nilai hasil thitung sebesar 4,724 $>$ tabel 1,976 dengan tingkat signifikansi 0,000 0,05 ini berarti variabel komitmen organisasi berpengaruh signifikan terhadap kinerja.

Uji untuk mengetahui bagaimana pengaruh self-efficacy, locus of control dan komitmen terhadap kinerja pendamping sosial PKH secara simultan dapat dilihat berdasarkan tabel dibawah ini :

Tabel 7. ANOVA

\begin{tabular}{|c|c|c|c|c|c|c|}
\hline \multirow{2}{*}{\multicolumn{2}{|c|}{ Model }} & \multirow{3}{*}{$\begin{array}{r}\text { Sum of Squares } \\
635,845\end{array}$} & \multicolumn{3}{|c|}{ Mean } & \multirow{3}{*}{$\frac{\text { Sig. }}{, 000^{\mathrm{b}}}$} \\
\hline & & & df & Square & $\mathrm{F}$ & \\
\hline \multirow[t]{3}{*}{1} & Regression & & 3 & 211,948 & 64,425 & \\
\hline & Residual & 480,315 & 146 & 3,290 & & \\
\hline & Total & 1116,160 & 149 & & & \\
\hline
\end{tabular}

sumber: Data diolah, 2019

Berdasarkan tabel 7, dapat dilihat $F_{\text {hitung }}$ sebesar 64,425 > Ftabel sebesar 2,67 dengan tingkat signifikansi $0,000<0,05$ sehingga dapat diartikan bahwa variabel self-efficacy, locus of control dan komitmen 
organisasi berpengaruh signifikan secara simultan terhadap kinerja Pendamping Sosial PKH Kabupaten Kebumen.

\section{Uji Koefisien Determinasi}

Pengujian ini digunakan untuk mengukur besarnya kontribusi variabel independen terhadap variabel dependen.

Tabel 8. Hasil Uji Koefisien Determinasi

\begin{tabular}{ccccc}
\hline Model & $\mathrm{R}$ & R Square & $\begin{array}{c}\text { Adjusted R } \\
\text { Square }\end{array}$ & $\begin{array}{c}\text { Std. Error of the } \\
\text { Estimate }\end{array}$ \\
\hline 1 &, $755^{\mathrm{a}}$ &, 570 &, 561 & 1,81379 \\
\hline
\end{tabular}

Sumber: Data diolah, 2019

Berdasarkan tabel 8 diatas, nilai koefisien determinasi (Adjusted $R^{2}$ ) di peroleh 0,561 artinya 56,10 \% variabel kinerja dipengaruhi oleh variabel self-efficacy, locus of control dan komitmen organisasi, sedangkan sisanya sebesar $43,90 \%$ dijelaskan oleh variabel lain yang tidak ada dalam penelitian ini.

\section{Pengaruh Self-Efficacy Terhadap Kinerja}

Sesuai dengan hasil regresi dan uji t variabel self-efficacy terhadap kinerja Pendamping Sosial PKH Kabupaten Kebumen tidak berpengaruh signifikan dengan hasil $t_{\text {hitung }}$ sebesar $0,657<t_{\text {tabel }} 1,976$ dengan tingkat signifikansi 0,512 >0,05 ini berarti variabel self-efficacy tidak mempunyai pengaruh signifikan terhadap kinerja. Hal ini sejalan dengan penelitian yang dilakukan oleh Dian Rizki Noviawati (2016). Implikasi manajerial dari penelitian ini adalah tidak diperlukannya peningkatan self-efficacy pendamping, karena self-efficacy tidak terlalu berpengaruh terhadap kinerja pendamping sosial itu sendiri, seperti adanya pelatihan tambahan dan diklat teknis.

\section{Pengaruh Locus of Control Terhadap Kinerja}

Sesuai dengan regresi dan hasil uji t variabel locus of control terhadap kinerja Pendamping Sosial PKH Kabupaten Kebumen menunjukan pengaruh yang positif dan signifikan yaitu hasil thitung sebesar 8,641 > $t_{\text {tabel }}$ 1,976 dengan tingkat signifikansi $0,000<0,05$ ini berarti variabel locus of control mempunyai pengaruh signifikan terhadap kinerja pendamping. Penelitian ini sejalan dengan peneltian yang dilakukan oleh Abdulloh (2006), Implikasi manajerial yang bisa disarankan adalah perlunya dukungan serta peningkatan locus of control, seperti budaya kedisiplinan, saling mendukung dalam kerja sama dan pembangunan sikap mental yang baik.

\section{Pengaruh Komitmen Organisasi Terhadap Kinerja}

Sesuai dengan uji regresi dan uji t variabel komitmen organisasi terhadap kinerja Pendamping Sosial PKH Kabupaten Kebumen menunjukan pengaruh yang positif dan signifikan yaitu hasil thitung sebesar 4,724 > $t_{\text {tabel }}$ 1,976 dengan tingkat signifikansi $0,000<0,05$ ini berarti variabel komitmen organisasi berpengaruh signifikan terhadap kinerja. Hal ini sejalan dengan penelitian yang dilakukan oleh Indra Gunawan (2013), yang menyatakan bahwa komitmen organisasi berpengaruh positif secara parsial terhadap kinerja karyawan. Implikasi manajerial dari penelitian ini adalah diperlukannya peningkatan komitmen organisasi, seperti pemenuhan kebutuhan dan loyalitas pegawai.

\section{SIMPULAN}

Berdasarkan hasil penelitian dan pembahasan serta mengacu pada perumusan masalah dan tujuan penelitian yang telah diuraikan maka dapat disimpulkan bahwa : 
1. Self-efficacy tidak berpengaruh terhadap kinerja Pendamping Sosial PKH Kabupaten Kebumen.

2. Locus of control secara berpengaruh positif dan terhadap kinerja Pendamping PKH Kabupaten Kebumen. Artinya semakin tinggi locus of control maka semakin tinggi kinerja pendamping PKH. Hal ini berarti locus of control dapat meningkatkan kinerja pendamping PKH Kabupaten Kebumen.

3. Komitmen organisasi secara parsial berpengaruh positif dan signifikan terhadap kinerja Pendamping PKH Kabupaten Kebumen. Artinya semakin tinggi komitmen organisasi maka semakin tinggi kinerja pendamping PKH. Hal ini berarti komitmen organisasi dapat meningkatkan kinerja pendamping PKH Kabupaten Kebumen.

Berdasarkan kesimpulan diatas maka dapat dikemukakan saran sebagai berikut:

Penelitian ini membuktikan bahwa variabel yang paling mempengaruhi kinerja Pendamping PKH Kabupaten Kebumen adalah locus of control. Karena itu locus of control pendamping PKH supaya ditingkatkan agar tercipta kinerja yang maksimal, yaitu dapat dengan cara meyakini bahwa dengan bekerja keras target kinerja dapat tercapai, saling membantu atau bekerjasama, Pelaksanaan terhadap visi dan misi organisasi yang lebih baik, pemberian kebebasan dalam berinisiatif, Penuhi kebutahan pendamping sesuai prosedur yang berlaku, pengawasan terhadap kedisiplinan kerja.

Komitmen organisasi mempunyai pengaruh positif dan signifikan terhadap kinerja pendamping sosial PKH. Sehingga komitmen organisasi juga perlu ditingkatkan agar tercipta kinerja Pendamping sosial PKH Kabupaten Kebumen yang maksimal, diantaranya setiap kegiatan yang berhubungan dengan organisasi atau yang diselenggarakan oleh organisasi harus diprioritaskan, tanamkan visi dan misi organisasi pada pendamping, berikan sanksi yang mendidik bagi pendamping yang melanggar peraturan dan lakukan penilaian dan pengawasan kinerja pendamping serta penegasan tentang komitmen dan tugas pendamping PKH sehingga tidak ada pendamping yang melakukan double job diluar PKH.

Self efficacy juga berpengaruh terhadap kinerja pegawai Pendamping sosial PKH Kabupaten Kebumen, karena tingkat pengaruh terhadap kinerja cukup kecil dibanding variabel locus of control dan komitmen organisasi, sehingga tidak perlu meningkatkan self efficacy pegawai.

Bagi peneliti lain, diharapkan untuk mengembangkan hasil penelitian ini dengan memperluas variabelvariabel bebas yang diperkirakan dapat mempengaruhi kinerja pendamping PKH Kabupaten Kebumen selain, self efficacy, locus of control dan komitmen organisasi karena hasil penelitian menyatakan masih terdapat pengaruh variabel-variabel lain sebesar $43,90 \%$ yang dapat mempengaruhi kinerja pendamping PKH Kabupaten Kebumen.

\section{REFERENSI}

Abdulloh. 2006. Pengaruh Budaya Organisasi, Locus of Control, dan Kepuasan Kerja Terhadap Kinerja Karyawan Pada Kantor Pelayanan Pajak Semarang Barat. Tesis Magister Manajemen (Tidak dipublikasikan), Semarang : Program Pascasarjana UNDIP.

Arikunto, S. 2002. Prosedur Penelitian Suatu Pendekatan Praktek, Edisi Revisi 3. Jakarta: Rineka Cipta.

Bandura, A. 1997. Self Efficacy -The Exercise of Control, (Fifth Printing, 2002). New York: W.H. Freeman \& Company.

Fadzilah, A. 2006. Analisis Pengaruh Pemberdayaan Karyawan dan self Of Efficacy terhadap Kinerja Karyawan Bagian Penjualan (StudiKasusPadaPT. Sinar Sosro Wilayah Pemasaran Semarang). Jurnal Studi Manajemen \& Organisasi, Vol 3(1).

Falikhatun. 2003. Pengaruh Budaya Organisasi, Lokus Of Control Dan Penerapan System Informasi Terhadap Aparat Unit-Unit Pelayanan Publik. Emprika, Vol 16(2): 263-281. 
Ghozali, I. 2009. Aplikasi Analisis Multivariate Dengan Program SPSS, Cetakan Keempat. Semarang: Badan Penerbit Universitas Diponegoro.

Gunawan, I. 2013. Pengaruh Komitmen Organisasi dan Locus of Control Terhadap Kinerja Karyawan PT. Nikkatsu Electric Works Bandung. Skripsi Sarjana (Tidak dipublikasikan). Bandung : Fakultas Ekonomi UNIKOM

Helmy, I., Adawiyah, W. R., dan Banani, A. 2019. Linking Psychological Empowerment, Knowledge Sharing, and Employees' Innovative Behavior in SMEs. The Journal of Behavioral Science, Vol 14(2): 6679.

Kreiter, R. dan Kinicki, A. 2003. Perilaku Organisasi, Edisi Pertama, Jakarta: Salemba Empat

Luthans, F. 2006. Perilaku Organisasi, (Alih Bahasa V.A Yuwono, dkk), Edisi Bahasa Indonesia, Yogyakarta: ANDI.

Nasution. 2006. Budaya Organisasi, Kepuasan Kerja, Komitmen Organisasi dan Keinginan Berpindah. Investigasi Empiris Pada Berbagai Unit Kerja di Universitas Bengkulu. Jurnal Bisnis dan Ekonomi, Vol 13(2).

Nitisemito, A. S. 2002. Manajemen Personalia. Edisi Ketiga, Cetakan Kesembilan, Jakarta; Ghalia Indonesia.

Nitisemito, A. S. 2006. Manajemen Personalia, Manajemen Sumber Daya Manusia. Ghalia Indonesia, Jakarta.

Prawirosentono, S. 2008. Manajemen Sumberdaya Manusia "Kebijakan Kinerja Karyawan". Yogyakarta: BPFE UGM.

Robbins, S. P. 2006. Perilaku Organisasi, Jakarta: Gramedia.

Sedarmayanti, 2007. Good Governance (Kepemerintahan Yang Baik) Dalam Rangka Otonomi Daerah : Upaya Membangun Organisasi Efektif dan Efisien Melalui Rekstrukturisasi dan Pemberdayaan. Bandung: Mandar Maju.

Sedarmayanti. 2009. Sumber Daya Manusia dan Produktivitas Kerja. Bandung: Mandar Maju.

Singaribuan, M. dan Effendi, S. 1989. Metode Penelitian Survey. LP3ES. Jakarta.

Sugiyono. 2010. Metode Kuantitatif Kualitatif dan R\&D. Bandung, Penerbit: Alfabeta

Suharti. 2015. Pengaruh Kompetensi, Budaya Organisasi Dan Lingkungan Kerja Terhadap Kepuasan Kerja Pegawai Pada PT. Rajawali Cipta Media Kebumen.Skripsi Sarjana, tak diterbitkan, STIE Putra Bangsa

Surahmawati. 2016. Kinerja Pendamping Program Keluarga harapan (PKH) di Kecamatan Pontianak Timur. Jurnal Publik (Ilmu Administrasi Negara), Vol 5(3).

Tintri, D. 2002. Pengaruh Struktur dan Kultur Organisasional Terhadap Keefektifan Anggaran Partisipasi Dalam Peningkatan Kinerja Manajerial. Jurnal Ekonomi dan Bisnis, Vol7(2): 59-68.

Umam, K. 2010. Perilaku Organisasi. Bandung. Pustaka Setia.

Umar, H. 2002. Metodologi Penelitian Aplikasi dalam Pemasaran. Edisi II, Jakarta: PT. Gramedia Pustaka Utama

Wibowo. 2011. Budaya Organisasi : sebuah kebutuhan untuk meningkatkan kinerja jangka panjang. Jakarta: Rajawali Pers. 
Fokus Bisnis: Media Pengkajian Manajemen dan Akuntansi Vol. 18, No. 2, Desember 2019

Widari, T. 2016. Pengaruh Lingkungan Dan Lingkungan Kerja Terhadap Kinerja Pegawai (Studi pada Badan Kepegawaian Daerah Daerah Istimewa Yogyakarta). Skripsi Sarjana (Tidak dipublikasikan). Yogyakarta : Fakultas Ekonomi Universitas Negeri Yogyakarta.

Winardi. 2004. Manajemen Perilaku Organisasi, Cetakan kedua. Kencana prenada Media Group. Jakarta. 